\title{
DOSES DE NITROGÊNIO E SUPERFOSFATO SIMPLES NO CRESCIMENTO DE MUDAS DE MAMOEIRO 'FORMOSA'
}

\author{
Doses of nitrogen and simple superphosphate on papaya 'Formosa' plant growth
}

\author{
Vander Mendonça ${ }^{2}$, Cristiane Pedrosa ${ }^{3}$, Nelson Pires Feldberg ${ }^{4}$, Nildo Antônio Arruda de Abreu ${ }^{5}$, \\ Ana Paula Ferreira de Brito ${ }^{3}$, José Darlan Ramos ${ }^{6}$
}

\begin{abstract}
RESUMO
Para avaliar as respostas de mudas de mamoeiro 'Formosa' ao efeito de doses de nitrogênio e do superfostato simples, foi conduzido um experimento, em viveiro telado (50\%) no Departamento de Agricultura da Universidade Federal de Lavras (UFLA). O delineamento utilizado foi em blocos casualizados, em esquema fatorial 4 x 4, com quatro repetições e cinco plantas por parcela. Utilizou-se 4 doses de nitrogênio $\left(0 ; 800 ; 1600 ; 3200 \mathrm{mg} \mathrm{N} \mathrm{dm}^{-3}\right.$ de substrato), e 4 doses de superfosfato simples $(0 ; 2,5 ; 5,0$ e 10,0 $\mathrm{kg} \mathrm{m}^{-3}$ de substrato). Foram avaliadas as seguintes características: altura da muda $(\mathrm{cm})$, comprimento da raiz $(\mathrm{cm})$, número de folha/ planta, matéria seca da parte aérea e da raiz (g/planta). Verificou-se que a utilização de adubações nitrogenada em cobertura garante melhor qualidade na formação de mudas de mamoeiro 'Formosa' e que dosagens elevadas promovem efeitos depressivos nas mudas. O superfosfato simples responde de maneira positiva quando utilizado na formulação do substrato para formação de mudas de mamoeiro até dosagens de $10 \mathrm{~kg} \mathrm{~m}^{-3}$.
\end{abstract}

Termos para indexação: Carica papaya, adubação nitrogenada e fosfatada.

\begin{abstract}
In order to evaluate responses of nitrogen and phosphorus fertilization on papaya 'Formosa' seedling growth one experiment was carried out in shady chamber light (50\%) at Agronomy Department of Universidade Federal de Lavras (UFLA). A randomized block design was used in a 4x 4 factorial scheme, with four replications and five plants per plot. It was used 4 doses of nitrogen ( 0 ; $800 ; 1600$ and $3200 \mathrm{mg} \mathrm{N} \mathrm{dm}^{-3}$ of substrate) and 4 doses of SS $\left(0 ; 2.5 ; 5.0 ;\right.$ and $10.0 \mathrm{~kg} \mathrm{~m}^{-3}$ of substrate). It was evaluated the following characteristics: high plant $(\mathrm{cm})$, root length $(\mathrm{cm})$, number of leaves/plant, dry matter of aerial part and root ( $\mathrm{g} / \mathrm{plant})$. Nitrogen covering fertilization warranted best quality of papaya seedling and higher dosages promoted negative effects. The simple super phosphate showed good of seedlings qualities when was used at $10 \mathrm{~kg} \mathrm{~m}^{-3}$ in substrate.
\end{abstract}

Index terms: Carica papaya, nitrogen and simple super phosphate fertilization.

(Recebido para publicação em 21 de outubro de 2004 e aprovado em 1 de abril de 2005)

\section{INTRODUÇÃO}

A espécie de mamoeiro (Carica papaya) é a mais cultivada em todo o mundo. No Brasil existem todas as condições edafoclimáticas favoráveis ao seu desenvolvimento, sendo tão comum em estado semisilvestre quanto cultivado (OLIVEIRA, 2000). As regiões Sudeste e Nordeste somam em média $87,5 \%$ da produção nacional, destacando-se os Estados do Espírito Santo e Bahia como os principais produtores. O País em 2001 produziu 1.489.324 toneladas em uma área cultivada de 37.299 ha (AGRIANUAL, 2004).

Um dos entraves da cadeia produtiva do mamão é a obtenção e manejo do material propagativo (RUGGIERO, 1988). Por ser uma cultura que necessite de uma grande densidade de plantas/ha e renovação dos pomares no máximo a cada três anos (SOUZA, 2000), há uma demanda constate por mudas.

Apesar da constatação que a cultura do mamoeiro absorve considerável quantidade de nitrogênio (SOUZA et al., 2000) e da importância da nutrição nitrogenada para o crescimento das plantas, há uma carência acentuada de pesquisas, na áreas de propagação, adubação, manejo cultural e fitossanitário entre outras (TEIXEIRA et al., 2004).

Para Morin (1967), é imprescindível a aplicação de fertilizantes minerais durante os estádios iniciais de crescimento e desenvolvimento da planta. Segundo este autor, a planta jovem apresenta certo retardamento, por qualquer deficiência nutricional, de modo que as aplicações subseqüentes não têm o mesmo efeito que o verificado em plantas adubadas apropriadamente desde o início de sua formação.

\footnotetext{
${ }^{1}$ Trabalho financiado com bolsa da CAPES.

2 Engenheiro Agrônomo, Dr. Professor Adjunto da Universidade Estadual de Mato Grosso do Sul/UEMS - Rod. MS 306, Km 6 - 79.540-000 Cassilândia, MS - vanderm@uems.br

${ }^{3}$ Graduandas em Agronomia pela Universidade Federal de Lavras/UFLA - Cx. P. 3037 - 37200-000 - Lavras, MG - cristianepedrosa@bol.com.br ${ }^{4}$ Engenheiro Agrônomo Mestrando em Agronomia/Fitotecnia/UFLA - Cx. P. 3037 - 37200-000 - Lavras, MG.

${ }^{5}$ Engenheiro Agrônomo, M. Sc. Departamento de Agricultura/UFLA - Cx. P. 3037 - 37200-000 - Lavras, MG.

${ }^{6}$ Engenheiro Agrônomo, Dr. Professor do Departamento de Agricultura/UFLA, Cx. Postal 3037 - 37200-000 - Lavras, MG - darlan@ufla.br
} 
Segundo Marschner (1997), o fósforo e o nitrogênio são os nutrientes que mais limitam o crescimento e o desenvolvimento do vegetal. A utilização do nitrogênio para produção de mudas em recipientes, tem proporcionado um rápido crescimento destas na fase de sementeira, principalmente para a produção de porta-enxertos de citros (DECARLOS NETO, 2000; ESPOSTI, 2000).

O fósforo é essencial para o crescimento normal das plantas e está entre os nutrientes com maior demanda. O P requerido para o ótimo crescimento das plantas varia conforme a espécie ou órgão analisado de 0,1 a $0,5 \%$ da matéria seca (VICHIATO, 1996). Além de promover a formação e o crescimento prematuro de raízes, melhora a eficiência no uso da água, e quando em alto nível no solo, ajuda a manter a absorção deste pelas plântulas, mesmo sob condições de alta tensão de umidade do solo (LOPES, 1989).

Mistura de terra com esterco e ou adubos minerais produziram mudas de mamoeiro mais vigorosas avaliadas por meio da altura, do comprimento das raízes e da massa da matéria seca total (FERNANDES et al., 2002).

Objetivou-se com este trabalho avaliar o crescimento de mudas mamoeiro 'Formosa' ao efeito de doses de nitrogênio e de superfostato simples e encontrar as melhores doses a serem recomendadas para a formação da muda.

\section{MATERIAL E MÉTODOS}

O experimento foi conduzido em bancadas de madeira suspensas a uma altura de $1 \mathrm{~m}$ do solo localizada em um viveiro de formação de mudas no Campus da Universidade Federal de Lavras (UFLA), Minas Gerais. O viveiro foi cercado com telado de nylon tipo sombrite, permitindo $50 \%$ de luminosidade no seu interior e uma boa ventilação.

As mudas utilizadas nesta pesquisa foram obtidas de sementes da empresa ISLA PAK, adquiridas em casas comerciais na cidade de Lavras-MG. Sendo utilizada a variedade Formosa com $71 \%$ de germinação e 99,9\% de pureza, conforme dados do fabricante.

Como substrato utilizou-se uma mistura com os componentes: composto orgânico + areia + solo na proporção de 1:1:3 em volume, com as seguinte composição químicas: $\mathrm{pH}=6,0 ; \mathrm{P}=15,0 \mathrm{mg} \mathrm{dm}^{-3} ; \mathrm{K}=72 \mathrm{mg}$ $\mathrm{dm}^{-3} ; \mathrm{Ca}=4,0 \mathrm{cmol}_{\mathrm{c}} \mathrm{dm}^{-3} ; \mathrm{Mg}=1,4 \mathrm{cmol} \mathrm{dm}_{\mathrm{c}}^{-3} ; \mathrm{Zn}=3,4 \mathrm{mg} \mathrm{dm}^{-3}$; $\mathrm{Fe}=49,6 \mathrm{mg} \mathrm{dm}^{-3} ; \mathrm{Mn}=20,7 \mathrm{mg} \mathrm{dm}^{-3} ; \mathrm{Cu}=2,0 \mathrm{mg} \mathrm{dm}^{-3} ; \mathrm{B}=1,0$ $\mathrm{mg} \mathrm{dm}{ }^{-3} ; \mathrm{S}=13,8 \mathrm{mg} \mathrm{dm}^{-3} ; \mathrm{SB}=5,6 \mathrm{cmol} \mathrm{dm}^{-3} ; \mathrm{T}=7,5 \mathrm{cmol} \mathrm{dm}^{-3}$ $\mathrm{V}=74,6 \%$ e matéria orgânica $=1,6 \mathrm{dag} \mathrm{\textrm {kg } ^ { - 1 }}$. O pH foi determinado em água, $\mathrm{KCl}$ e $\mathrm{CaCl}_{2}$ - relação 1:2,5. O P, K,
$\mathrm{Fe}, \mathrm{Zn}, \mathrm{Mn}$ e $\mathrm{Cu}$ foram determinados por extrator de Mehlich 1. O Ca e o $\mathrm{Mg}$ foram determinados por extrator $\mathrm{KCl} 1 \mathrm{~N}$. O B foi determinado por extrator água quente e o $\mathrm{S}$ por extrator fosfato monocálcico em ácido acético. A matéria orgânica foi determinada por oxidação: $\mathrm{Na}_{2} \mathrm{Cr}_{2} \mathrm{O}_{7} 4 \mathrm{~N}+$ $\mathrm{H}_{2} \mathrm{SO}_{4} 10 \mathrm{~N}$.

As sementes foram semeadas em sacos plásticos $(10 \times 20 \mathrm{~cm})$ furados lateralmente, com capacidade para 500 $\mathrm{mL}$. Foram utilizadas duas sementes por recipiente e quando estas atingiram $5 \mathrm{~cm}$ foram desbastadas deixandose a mais vigorosa. Em seguida, iniciaram as aplicações de $\mathrm{N}$ sendo repetidas cinco vezes. Em cada aplicação, foram adicionados aos sacos de polietileno, $20 \mathrm{~mL}$ de solução de cada tratamento na forma de uréia contendo $45 \%$ de nitrogênio.

O delineamento utilizado foi em blocos casualizados, em esquema fatorial 4 x 4, com quatro repetições e cinco plantas por parcela. Utilizou-se quatro doses de nitrogênio ( $0 ; 800 ; 1600 ; 3200 \mathrm{mg} \mathrm{N} \mathrm{dm}^{-3}$ de substrato), e quatro doses de superfosfato simples $\left(0 ; 2,5 ; 5,0\right.$ e $10,0 \mathrm{~kg} \mathrm{~m}^{-3} \mathrm{de}$ substrato). A adução com o superfosfato simples foi realizada na época de enchimento dos sacos de polietileno.

Os tratos culturais utilizados foram a irrigação (de manhã e a tarde), com utilização de regador manual, controle de pragas e doenças e, a monda das plantas daninhas.

As variáveis avaliadas, aos 140 dias após a semeadura, foram: altura de muda $(\mathrm{cm})$, medida a partir do colo da muda até a gema apical; comprimento de raiz $(\mathrm{cm})$ medida a partir do colo da muda até a extremidade da raiz e número de folha/planta. Posteriormente, as partes foram colocadas em estufa à temperatura de $65^{\circ} \mathrm{C}$, até atingir peso constante. Após isso, foram efetuadas pesagens, encontrando-se assim a matéria seca da parte aérea e da raiz.

Os dados foram submetidos à análise de variância e para as médias foi utilizada a análise de regressão (GOMES, 2000). As análises foram realizadas pelo programa computacional Sistema para Análise de Variância - SISVAR (FERREIRA, 2000).

\section{RESULTADOS E DISCUSSÃO}

Pela análise de variância apresentada na Tabela 1 , verificam-se os efeitos significativos pelo teste $\mathrm{F}(\mathrm{p}<0,01)$ para a interação das doses de nitrogênio e superfosfato apenas para a altura da muda. Para as demais variáveis houve efeito dos dois fatores separadamente.

A resposta para a altura da muda, 140 dias após a semeadura, seguiu um comportamento quadrático para as doses de nitrogênio dentro das dosagens de superfosfato simples sendo que a melhor resposta $(17,7 \mathrm{~cm})$ foi

Ciênc. agrotec., Lavras, v. 30, n. 6, p. 1065-1070, nov./dez., 2006 
observada na dose $2.191 \mathrm{mg} \mathrm{N} \mathrm{dm}^{-3}$ juntamente com 2,5 $\mathrm{kg} \mathrm{m}^{-3}$ de superfosfato simples (Figura 1). A partir destas dosagens houve efeito contrário, caracterizado como super dosagem de $\mathrm{N}$, podendo ter ocorrido diminuição do $\mathrm{pH}$ do substrato, ocasionado por uma possível liberação do $\mathrm{H}^{+}$produzido durante o processo de nitrificação da uréia aplicada, conforme é relatado por DeCarlos Neto et al. (2002) ou ter ocasionado um desequilíbrio nutricional pelo excesso do $\mathrm{N}$ nas plantas. Resultados semelhantes foram encontrados Teixeira et al. (2004), que verificaram que a utilização de sulfato de amônio em cobertura, proporcionou em média, um incremento na altura das mudas de mamoeiro $112,5 \%$ superiores às mudas que não foram adubadas com $\mathrm{N}$ em cobertura independente do substrato utilizado. Já De Carlos Neto et al. (2002) verificaram queda da altura dos porta-enxertos de citros com a utilização de elevadas dosagens de $\mathrm{N}$ (3200 $\mathrm{mg} \mathrm{N} \mathrm{dm}^{-3}$ ), propagados em tubetes.

A resposta para o comprimento da raiz em função das doses de nitrogênio é apresentada na Figura 2. Verificou-se também que a resposta segue um comportamento quadrático com a dose máxima de 1.545 $\mathrm{mg} \mathrm{N} \mathrm{dm}^{-3}$, proporcionando comprimento da raiz de $14,35 \mathrm{~cm}$.

Para o número de folhas, o comportamento das doses de nitrogênio também seguiu o modelo quadrático com o maior número de folhas de 7,94 em média, obtido na dose máxima de $1.333 \mathrm{mg} \mathrm{N} \mathrm{dm}^{-3}$ (Figura 3). Teixeira et al. (2004) também constataram aumentos no número de folhas de mudas de mamoeiro 'Sunrise Solo' com utilização de substrato puro enriquecido com $\mathrm{N}$ em cobertura.

Os dois fertilizantes proporcionaram efeitos positivos nas variáveis matéria seca da parte aérea e raiz. Para a matéria seca da parte aérea, as doses de nitrogênio tiveram um efeito positivo até a dose máxima de $2.330 \mathrm{mg}$ $\mathrm{N} \mathrm{dm}^{-3}$, quando o valor desta variável foi de $0,93 \mathrm{~g}$. Em relação às doses do superfosfato simples o comportamento foi linear crescente com a melhor resposta $(0,27$ g) obtida na maior dosagem (Figura 4). Já para a matéria seca da raiz a resposta das dosagens de $\mathrm{N}$ e do superfosfato simples seguiram um modelo de comportamento linear crescente com as melhores respostas sendo obtidas nas maiores dosagens dos dois fertilizantes (Figura 5).

Verifica-se que houve aumento de todas as variáveis analisadas até um ponto ótimo, por meio da aplicação de N. Entretanto, altas dosagens de $\mathrm{N}$ proporcionaram efeito depressivos nas mudas de mamoeiro. Resultados semelhantes também foram observados por Carvalho \& Souza (1996) com utilização de elevadas dosagens de N no crescimento de limoeiro 'Cravo' e da tangerineira 'Cleópatra' em bandejas.

TABELA 1 - Resumo da análise de variância para a altura da muda, comprimento da raiz, número de folhas, matéria seca da parte aérea e da raiz em função das doses de nitrogênio e do superfosfato simples no crescimento de mudas de mamoeiro ‘Formosa'. Lavras-MG, 2004.

\begin{tabular}{ccccccc}
\hline Fontes de Variação & GL & $\begin{array}{c}\text { Altura } \\
(\mathbf{c m})\end{array}$ & $\begin{array}{c}\text { Comprimento } \\
\text { da raiz }(\mathbf{c m})\end{array}$ & $\begin{array}{c}\mathbf{N}^{\circ} \text {. de } \\
\text { folhas }\end{array}$ & $\begin{array}{c}\text { Matéria seca da } \\
\text { parte aérea }(\mathbf{g})\end{array}$ & $\begin{array}{c}\text { Matéria seca } \\
\text { da raiz }(\mathbf{g})\end{array}$ \\
\hline Nitrogênio (N) & 3 & $153,23955^{* *}$ & $15,716231^{* *}$ & $29,9456^{* *}$ & $1,079080^{* *}$ & $0,064596^{* *}$ \\
Superfosfato simples (SS) & 3 & $3,312527 \mathrm{~ns}$ & $3,212018 \mathrm{~ns}$ & $1,05854 \mathrm{~ns}$ & $0,520333^{* *}$ & $0,044977^{* *}$ \\
N x SS & 9 & $8,695775^{* *}$ & $3,887807 \mathrm{~ns}$ & $0,21354 \mathrm{~ns}$ & $0,075175 \mathrm{~ns}$ & $0,0097 \mathrm{~ns}$ \\
Bloco & 3 & 16,891293 & 9,622765 & 2,32895 & 0,051036 & 0,014043 \\
Resíduo & 36 & 2,839101 & 2,069658 & 1,27031 & 0,055006 & 0,004888 \\
\hline CV(\%) & & 13,88 & 10,53 & 16,80 & 37,72 & 41,02 \\
\hline
\end{tabular}

** Significativo a $1 \%$ de probabilidade pelo teste F; * Significativo a $5 \%$ de probabilidade pelo teste $\mathrm{F}$ e ns Nãosignificativo 
A aplicação de doses de $\mathrm{N}$, utilizando uréia em cobertura e do superfosfato simples favoreceu significativamente no aumento da matéria seca das mudas de mamoeiro. Quando se compara o valor da matéria seca da parte aérea da testemunha $(0,233 \mathrm{~g})$ com a matéria seca da parte aérea na dose ótima de $\mathrm{N}\left(3.000 \mathrm{mg} \mathrm{N} \mathrm{dm}^{-3}\right)$ que foi de $0,93 \mathrm{~g}$, verifica-se um ganho superior a $200 \%$, confirmando que a utilização deste elemento se faz necessário para a formação de mudas deste fruteira. $\mathrm{O}$ mesmo aconteceu com o superfosfato simples que proporcionou aumento considerável na matéria seca das mudas do mamoeiro. Cardoso et al. (1992), utilizando aplicações de superfosfato simples $\left(1,25 ; 2,5\right.$ e $\left.5,0 \mathrm{~kg} \mathrm{~m}^{-3}\right)$, também constataram incrementos na altura das mudas, na matéria seca da parte aérea e das raízes de mudas de cafeeiro 'Mundo Novo' e 'Catuaí em recipientes. Souza et al. (2003) concluíram que a aplicação de superfosfato simples na dose de $5 \mathrm{~kg} \mathrm{~m}^{-3}$ de substrato com $40 \%$ de vermicomposto proporcionaram a obtenção de mudas de gravioleira com qualidade superiores às demais porém, doses acima de $5,0 \mathrm{~kg} \mathrm{~m}^{-3}$ de superfosfato simples promovem efeitos negativos, o que não foi verificado com as mudas de mamoeiro 'Formosa' que responderam de maneira positiva até a maior dose utilizada neste trabalho. Em mudas de mamoeiro, Oliveira (2000) constatou que a utilização de doses de superfosfato triplo provocaram aumentos na produção da matéria seca das mudas. Segundo este autor as respostas encontradas demonstram que esta espécie é exigente em fósforo, cuja ausência limitou severamente o crescimento das mudas.

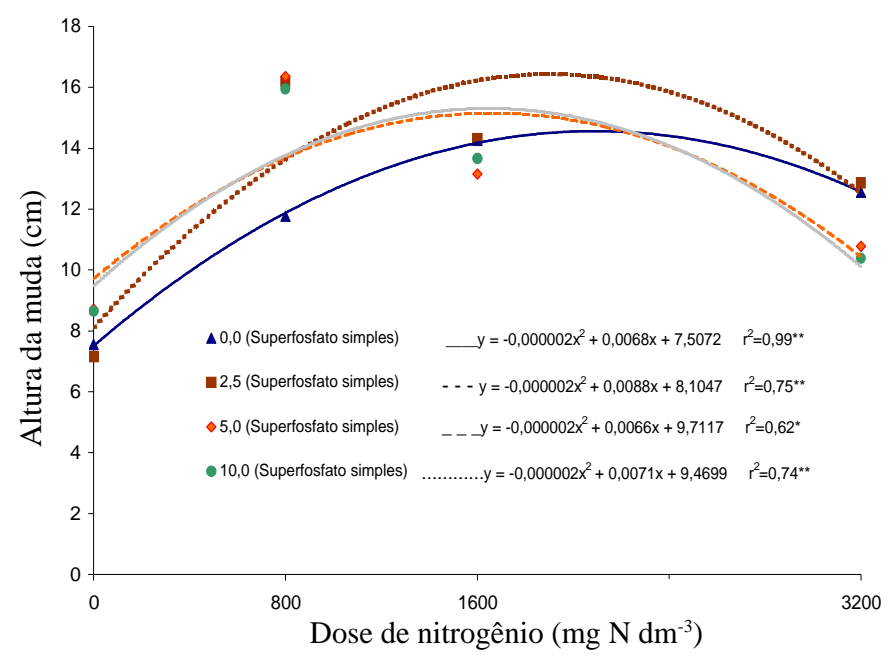

FIGURA 1 -Altura de mudas de mamoeiro em função da aplicação de nitrogênio e superfosfato simples. Lavras-MG, 2004.

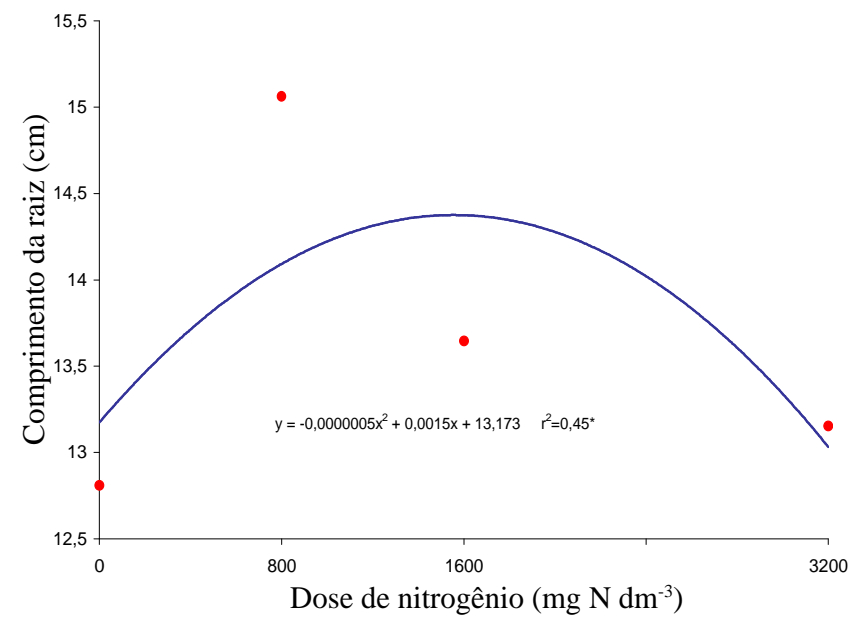

FIGURA 2 - Comprimento da raiz de mudas de mamoeiro em função da aplicação de nitrogênio. Lavras-MG, 2004.

Ciênc. agrotec., Lavras, v. 30, n. 6, p. 1065-1070, nov./dez., 2006 


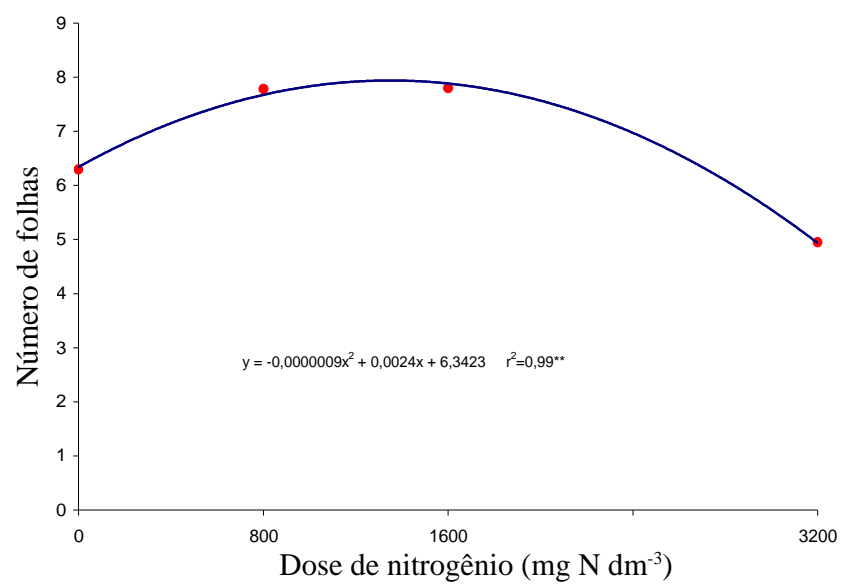

FIGURA 3 - Número de folhas de mudas de mamoeiro em função da aplicação de nitrogênio. Lavras-MG, 2004.

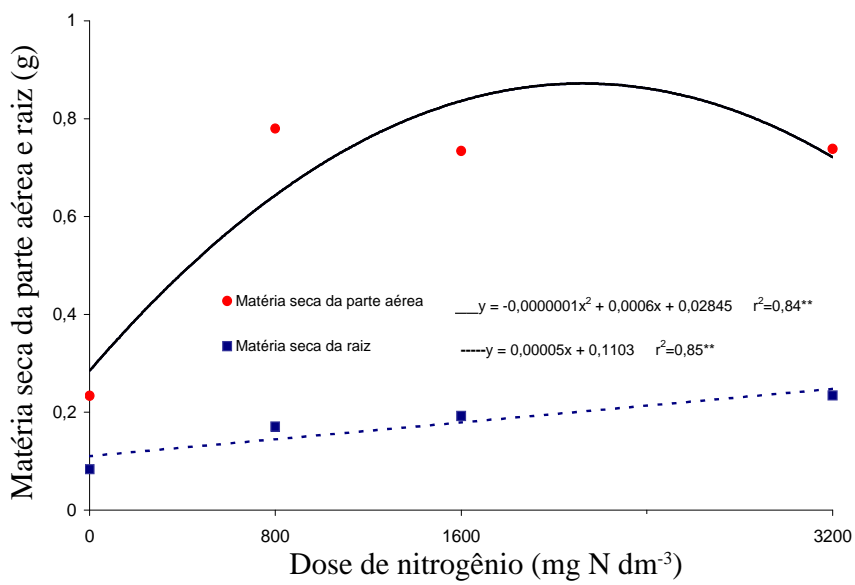

FIGURA 4 - Matéria seca da parte aérea e da raiz de mudas de mamoeiro em função da aplicação de nitrogênio. LavrasMG, 2004.

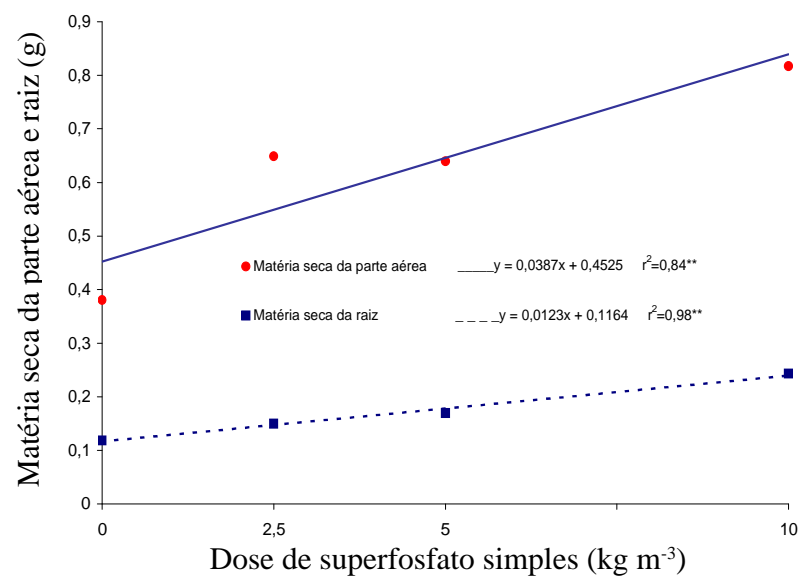

FIGURA 5 - Matéria seca da parte aérea e da raiz de mudas de mamoeiro em função da aplicação do superfosfato simples. Lavras-MG, 2004.

Ciênc. agrotec., Lavras, v. 30, n. 6, p. 1065-1070, nov./dez., 2006 


\section{CONCLUSÕES}

A utilização de adubação nitrogenada em dosagens de até $2.770 \mathrm{mg} \mathrm{N} \mathrm{dm}^{-3}$ em cobertura, garante melhor qualidade na formação de mudas de mamoeiro 'Formosa'.

O superfosfato simples responde de maneira positiva quando utilizado na formulação do substrato para formação de mudas de mamoeiro até dosagens de $10 \mathrm{~kg} \mathrm{~m}^{-3}$.

\section{REFERÊNCIAS BIBLIOGRÁFICAS}

AGRIANUAL. Anuário estatístico do Brasil. São Paulo: FNP Consultoria \& Comércio, 2004. 536 p.

CARDOSO, E. L.; ALVARENGA, G.; CARDOSO, M. M. de; CARVALHO, J. G. de. Efeito de doses de superfosfato simples em substrato, sobre o desenvolvimento de mudas de cafeeiro (Coffea arabica L.) "Mundo Novo" e "Catuaî". Ciência e Prática, Lavras, v. 16, n. 1, p. 35-38, 1992.

CARVALHO, S. A.; SOUZA, M. Doses e freqüência de aplicação de nitrato de potássio no crescimento de limoeiro 'Cravo' e da tangerineira 'Cleópatra' em bandejas. Pesquisa Agropecuária Brasileira, Brasília, v. 31, n. 11, p. 815-822, 1996.

DECARLOS NETO, A. Adubação e nutrição nitrogenada de porta-enxertos de citros, semeados em tubetes. 2000. 131 f. Dissertação (Mestrado) - Universidade Federal de Viçosa, Viçosa, 2000.

DECARLOS NETO, A.; SIQUEIRA, D. L. de; PERREIRA, P. R.G.; ALVAREZ, V. H. Crescimento de porta-enxertos de citros em tubetes influenciados por doses de N. Revista Brasileira de Fruticultura, Jaboticabal, v. 24, n. 1, p. 199-203, 2002.

ESPOSTI, M. D. D. Adubação e nutrição nitrogenada de porta-enxertos de citros produzidos em citrovasos. 2000. 96 f. Dissertação (Mestrado) - Universidade Federal de Viçosa, Viçosa, 2000.

FERNANDES, F. M.; CANASIN, R. C. F. S.; CORRÊA, L. de S. Adubação orgânica e/ou mineral no crescimento de mudas de mamoeiro (Carica papaya L.). In: CONGRESSO BRASILEIRO DE FRUTICULTURA, 17., 2002, Belém. Anais... Belém: SBF, 2002. CD-ROM.

FERREIRA, D. F. Análise estatística por meio do SISVAR (Sistema para Análise de Variância) para Windows versão 4.0. In: REUNIÃO ANUAL DA REGIÃO BRASILEIRA DA
SOCIEDADE INTERNACIONAL DE BIOMETRIA, 45., 2000, São Carlos. Anais... São Carlos: UFSCar, 2000. p. 255-258.

GOMES, F. P. Curso de estatística experimental. 14. ed. Piracicaba: USP, 2000. 477 p.

LOPES, A. S. Manual de fertilidade do solo. Piracicaba: Fundação Cargill, 1989. 177 p.

MARSCHNER, H. Mineral nutrition of higher plants. 2. ed. San Diego: Academic, 1997. 889 p.

MORIN, C. El papayo. In: Cultivo de frutales tropicales. 2. ed. Lima: ABC, 1967. p. 231-238.

OLIVEIRA, P. R. A. de. Efeito do fósforo e zinco na nutrição de mamoeiro e mangabeira. 2000. 184 p. Tese (Doutorado em Fitotecnia) - Universidade Federal de Lavras, Lavras, 2000.

RUGGIERO, C. Mamão. Jaboticabal: FCAV Unesp, 1988. 428 p.

SOUZA, C. A. S.; CORRÊA, F. L. de O.; MENDONÇA, V.; CARVALHO, J. G. de. Crescimento de mudas de gravioleira (Anonna muricata L.) em substrato com superfosfato simples e vermicomposto. Revista Brasileira de Fruticultura, Jaboticabal, v. 25, n. 3, p. 453-456, 2003.

SOUZA, J. S. Aspecto socioeconômicos. Mamão produção: aspecto técnico. Brasília, DF: Embrapa Comunicação para transferência de tecnologia, 2000. 10 p. (Frutas do Brasil, 3).

SOUZA, L. F. S.; TRINDADE, A. V.; OLIVEIRA, A. G. Calagem, exigências nutricionais e adubação. In: TRINDADE, A. V. (Org.). Mamão produção: aspectos técnicos. Cruz das Almas: Embrapa mandioca e Fruticultura; Brasília, DF: Embrapa Comunicação e transferência de tecnologia, 2000. 77 p. (Frutas do Brasil).

TEIXEIRA, J. D.; PEIXOTO, J. R.; VASCONCELOS, D. R.; PIRES, M. de C.; FLEURY, R. C.; MELO, B. Desenvolvimento de mudas de mamoeiro em diferentes substratos químicos e orgânicos, sob telado. In: CONGRESSO BRASILEIRO DE FRUTICULTURA, 18., 2004, Florianópolis. Anais... Florianópolis: SBF, 2004. CD-ROM.

VICHIATO, M. Influência da fertilização do porta-enxerto tangerineira (Citrus reshni Hort. Ex Tan. cv. Cleópatra) em tubetes, até a repicagem. 1996. 82 f. Dissertação (Mestrado em Agronomia) - Universidade Federal de Lavras, Lavras, 1996.

Ciênc. agrotec., Lavras, v. 30, n. 6, p. 1065-1070, nov./dez., 2006 